\title{
Prevalence of cigarette smoking and its related factors among Iranian male workers
}

\author{
Abbas Abbasi-Ghahramanloo, Leila Janani*2 (D), Seyed Kazem Malakouti ${ }^{3}$, Mahshid Rabetian ${ }^{3}$, Shahnaz Rimaz $^{* 4}$ (D)
}

Received: 17 Jul 2019

Published: 5 Nov 2020

\section{Abstract}

Background: Smoking is considered as the second leading risk factor of early death and disability throughout the world. Smoking is the second leading risk factor of early death and disability in the world. The workplace is an important setting for the implementation of cigarette smoking prevention and control interventions. This study aimed to determine the prevalence of cigarette smoking and related factors by focusing on ADHD and risk-taking behaviors among a sample of Iranian workers.

Methods: This cross-sectional study was conducted on 2434 male workers of Kaveh Industrial City in Saveh. Random cluster sampling was used in the selection of workers. All workers completed five sets of anonymous and validated questionnaires. ADHD was measured by Conner's Adult ADHD Rating Scales. Data analysis was done using chi-square, independent t-test and logistic regression model in STATA 10 . Also, P-value $<0.05$ was considered statistically significant.

Results: The mean age of the workers was $32.80 \pm 7.05$ years. The prevalence of cigarette smoking in the lifetime, last year, last month, and daily or almost daily in the last month were $26.2 \%, 20.6 \%, 18.5 \%$, and $13.1 \%$ respectively. After adjustment, age $(\mathrm{OR}=1.08)$, sensation seeking $(\mathrm{OR}=1.57)$, hookah smoking $(\mathrm{OR}=4.21)$, alcohol use $(\mathrm{OR}=2.51)$, sexual risk behaviors $(\mathrm{OR}=2.25)$, religiosity $(\mathrm{OR}=0.95)$ and self-esteem $(\mathrm{OR}=2.02)$ were associated with cigarette smoking.

Conclusion: Our results showed that $13.1 \%$ of workers were regular smokers (daily or almost daily). Specific programs in workplaces, including interventions to enhance self-steam and reduce anxiety, can be effective in lowering cigarette smoking prevalence. Also, comprehensive interventions to reduce or prevent different risk-taking behaviors can be considered as elements of preventive action plans.

Keywords: Cigarette smoking, Risk taking behaviors, ADHD, Male workers

Conflicts of Interest: None declared

Funding: This study was supported by grant No 96-03-27-31802 from Iran University of Medical Sciences.

\section{*This work has been published under CC BY-NC-SA 1.0 license.}

Copyright $₫$ Iran University of Medical Sciences

Cite this article as: Abbasi-Ghahramanloo A, Janani L, Malakouti SK, Rabetian M, Rimaz Sh. Prevalence of cigarette smoking and its related factors among Iranian male workers. Med J Islam Repub Iran. 2020 (5 Nov);34:150. https://doi.org/10.47176/mjiri.34.150

Corresponding author: Dr Leila Janani, janani.l@iums.ac.ir Dr Shahnaz Rimaz, rimaz.sh@iums.ac

1. Department of Public Health, School of Health, Ardabil University of Medical Sciences, Ardabil, Iran

2. Preventive Medicine and Public Health Research Center, Psychosocial Health Research Institute (PHRI) \& Department of Biostatistics, School of Public Health, Iran University of Medical Sciences, Tehran, Iran

3. Mental Health Research Center, Tehran Institute of Psychiatry-School of Behavioral Sciences and Mental Health, Iran University of Medical Sciences, Tehran, Iran

4. Radiation Biology Research Center, Department of Epidemiology, School of Public Health, Iran University of Medical Sciences, Tehran, Iran

\section{$\uparrow$ What is "already known" in this topic:}

Workers usually expose to occupational hazards, which can have adverse health effects. Furthermore, additional workplace stress and dissatisfaction might contribute to increased smoking. Actually, cigarette smoking may be a way of coping with these situations to get short term relief. There are some factors like cognitive, neurobiological and genetic ones that can play key roles in the ADHD-cigarette smoking association. But this association mostly assessed among children and adolescents in the world generally and especially in Iran. In Iran, some studies reported adult ADHD prevalence among specific populations like university students and prisoners.

\section{$\rightarrow$ What this article adds:}

- Almost $13 \%$ of workers were regular smokers (daily or almost daily).

- A higher score of religiosity had a protective effect on cigarette smoking.

- There was a co-occurrence of risk-taking behaviors among workers.

-ADHD and anxiety didn't show a significant effect on cigarette smoking. 


\section{Introduction}

According to the World Health Organization (WHO) report in 2015, over 1.1 billion people smoked tobacco. Based on this report, there is a declining trend in the prevalence of tobacco smoking in many countries, but tobacco smoking appears to be increasing in the Eastern Mediterranean and the Africa region (1). Also smoking reported as a second leading risk factor of early death and disability throughout the world in 2015 (2).

Based on the Global Burden of Disease Study (GBD) in 2015 , it is estimated that the prevalence of daily smoking was $25.0 \%$ in the world (3). In Iran, based on national surveys, the prevalence of cigarette smoking reported as $12.3 \%$ to $27.7 \%$ in men (4).

Workers usually expose to occupational hazards, which can have adverse health effects. Furthermore, additional workplace stress and dissatisfaction might contribute to increased smoking. Actually, cigarette smoking may be a way of coping with these situations to get short term relief (5). From the public health view, the workplace is an important setting for the implementation of cigarette smoking prevention and control interventions. These interventions include anti-tobacco messages, tobacco-free laws covering worksites and comprehensive coverage for cigarette cessation treatments for workers. Prior studies showed the effectiveness of smoke-free workplace policies (6-8).

There is no worldwide estimation of cigarette smoking among workers, but in some countries like the U.S there are several studies that reported smoking prevalence among this stratum. For example, Girija et al. reported that among workers in the construction industry, $24.4 \%$ were cigarette smokers (6). In some Asian countries, there are some studies about cigarette smoking among workers. For example, the current prevalence of cigarette smoking reported as $50.6 \%$ in manual workers in Korea (9).

Most of the previous research focused on the association between smoking and comorbid psychiatric disorders. For example, it is indicated that the prevalence of cigarette smoking among individuals with a history of comorbid psychiatric diagnosis is significantly higher than this rate in the general population $(10,11)$. ADHD is one of the most prevalent mental health disorders in childhood and it is estimated that it occurs among $4-5 \%$ of adults $(12,13)$. There are some factors like cognitive, neurobiological and genetic ones that can play a key role in the ADHDcigarette smoking association (14). But this association mostly assessed among children and adolescents in the world generally and especially in Iran. In Iran, some studies reported adult ADHD prevalence among specific populations like university students (15) and prisoners (16), but to the best of authors' knowledge, there is no information about the association between cigarette smoking and ADHD in Iranian adults especially workers.

The information about the cigarette smoking prevalence in workers can be useful in designing programs for preventing the development of smoking in this high-risk population.
Unfortunately, there is limited information on cigarette smoking and its related factors in workers in Iran. This study aimed to determine the prevalence of cigarette smoking and identify some factors related to cigarette smoking by focusing on ADHD and risk-taking behaviors among a sample of Iranian workers.

\section{Methods}

\section{Study population and sampling framework}

The present cross-sectional study was conducted from October 2017 to February 2019. In this study, a sample of 2434 workers was chosen by random cluster sampling from Kaveh Industrial City in Saveh.

All workers of the Kaveh Industrial City were eligible to enter into this study. The needed information collected through interviews and questionnaires. Before data collection, trained interviewers presented some explanations about the aims of the study, anonymity of the questionnaires, and voluntary nature of the participation in the study. Also, workers were asked not to write any personal information in the questionnaires. All workers had signed an informed consent form.

The questionnaire aimed to obtain information on cigarette and hookah smoking, alcohol use, illicit drug use, sexual risk behaviors, religious beliefs, ADHD, anxiety, and self-esteem as well as demographic information.

The first part of this questionnaire was prepared based on Alcohol, Smoking, and Substance Involvement Screening Test (ASSIST) developed by the WHO with consideration of the current status of substance use in Iran. This questionnaire was validated by a group of researchers previously $(17,18)$.

The Persian version of Conner's Adult ADHD Rating Scales (The self-reported short version, PCAARS-S; SV) was used to collect data about ADHD status among workers. This questionnaire was validated by SadeghiBazargani et al. and used to screen for adult ADHD in Tabriz, northwest of Iran (19).

Self-esteem was measured by the Persian version of the Rosenberg questionnaire (20). The participants were asked to choose one of the following responses: "1) strongly agree, 2) agree, 3) disagree, and 4) strongly disagree. Half of the questions were "negative" and reversely scored. The minimum and maximum possible values of this questionnaire were 10 and 40 respectively. In this scoring, higher scores indicate greater self-esteem.

Anxiety was measured using the Beck Anxiety Inventory (BAI). This questionnaire is a self-report assessment of anxiety symptoms and includes 21 items rated on a 4point Likert scale from 0 (not at all) to 3 (severely). The validity and reliability of the Persian version of this questionnaire were done by Kaviani and Mousavi (21).

Sensation seeking was assessed using the question "Do you enjoy doing things that are dangerous or risky?" workers who answered "yes" were considered as engaging in sensation seeking. 


\section{Statistical analysis}

The prevalence of cigarette smoking was reported with a $95 \%$ confidence interval (CI). For cigarette and hookah smoking, sexual risk behavior, and alcohol use, the last year was considered, while for illicit drug use lifetime use was considered for statistical analysis. To perform simple statistical analysis, chi-square and independent t-test were used. For estimation crude odds ratios and adjusted ones, univariate and multiple logistic regression models were used respectively. The hosmer-Lemeshow guideline was used for variable selection in a multiple model (22). All analyses were done using STATA 10 with considering survey analysis. P-value $>0.05$ was considered statistically significant.

\section{Results}

This study indicated that the mean age of the workers was found to be $32.80 \pm 7.05$ (range: 18-67) years. Among all workers, $716(29.4 \%)$ of them had academic education and only $38(1.6 \%)$ were illiterate. Most of the workers were married and only $58(2.4 \%)$ of workers had selfinjury experience. Also, 505 (20.7\%) of workers reported that they have sensation seeking.

As shown in Table 1, the lifetime, last year, last month

Table 1. Prevalence of Cigarette smoking in a sample of Iranian workers

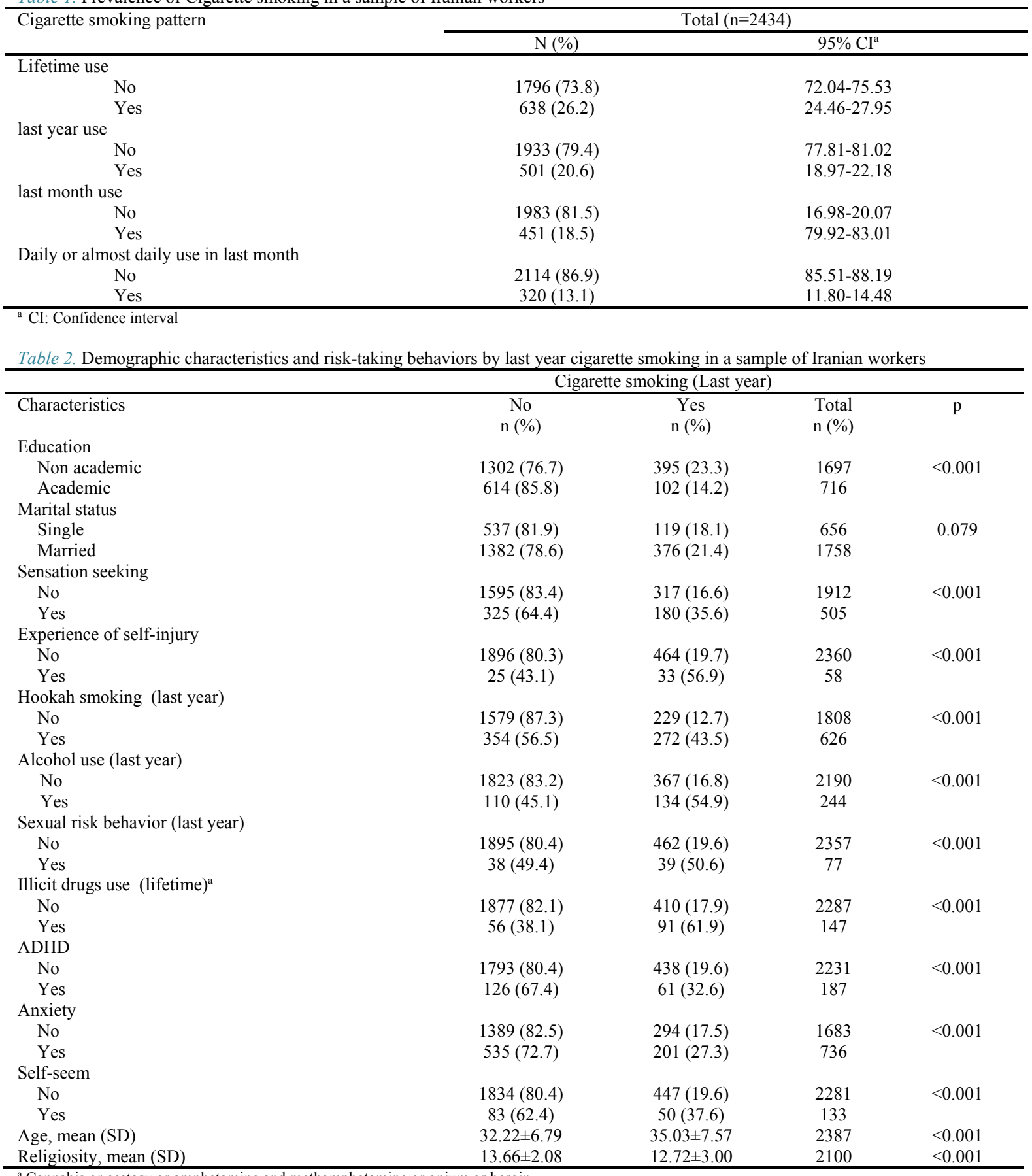

${ }^{\text {a }}$ Cannabis or ecstasy or amphetamine and methamphetamine or opium or heroin 
and daily or almost daily use of cigarette smoking in the last month were $26.2 \%$ (95\% CI: 24.46-27.95), 20.6\% (95\% CI: 18.97-22.18), 18.5\% (95\% CI:16.98-20.07) and $13.1 \%$ (95\% CI: $11.80-14.48)$ respectively.

The distribution of the last-year cigarette smoking by ADHD, risk-taking behaviors and some related factors are illustrated in Table 2. The results indicated that education, sensation seeking, the experience of self-injury, hookah smoking, alcohol use, sexual risk behavior, illicit drug use, age, ADHD index, anxiety, religiosity and selfesteem were significantly related to cigarette smoking.

A logistic model was used to estimate the crude ORs for all of the variables (Table 3 ). The results showed that illicit drug use has the highest OR among all variables. This analysis indicated that having ADHD has a significant effect on cigarette smoking in univariate analysis. In the final model, ADHD didn't show any significant effect on cigarette smoking.

To control the possible confounding effect of other variables, we performed multiple logistic models. The result of this analysis showed that after adjustment for other factors, age $(\mathrm{OR}=1.08)$, sensation seeking $(\mathrm{OR}=1.57)$, hookah smoking $(\mathrm{OR}=4.21)$, alcohol use $(\mathrm{OR}=2.51)$, sexual risk behaviors $(O R=2.25)$, religiosity $(O R=0.95)$ and self-esteem $(\mathrm{OR}=2.02)$ were associated with cigarette smoking.

\section{Discussion}

In this study, the lifetime, last year, last month, and daily or almost daily prevalence of cigarette smoking was found to be $26.2,20.6,18.5$, and $13.1 \%$ respectively. In the National Health Interview Survey (NHIS) study among U.S adults, the prevalence of current smoking in males was found to be $17.5 \%$ in 2016 (23). The prevalence of daily, regular and current cigarette smoking reported as 15, 16 and $18 \%$ among the Australian adults in 2016 (24). Based on national surveys among adults, the prevalence of current cigarette smoking was found to be $25.6 \%$ in $2000,21.5 \%$ in $2005,24.9 \%$ in 2007 and $21.3 \%$ in 2011 in Iranian males (25). Based on different target populations, cultural and social norms as well as the difference in the definition of smoking in above-mentioned studies, it isn't logical to compare the finding of the pre- sent study with these national studies. In spite of the difference in the definition of being smoker and other related factors, the comparison of finding with previous studies among workers seems to be valuable. Current cigarette smoking was reported as $28.1 \%$ among workers in a dusty industry in New Jersey in 2016 (26), 57\% among industrial workers in Greece in 2006 (27), 50.6\% among manual male workers in Korea in 2012 (9), 23.1\% among male industrial workers in Brazil in 2001 (28) and 23.4\% among male industrial workers in India (29). These broad ranges could be related to lots of factors such as domestic rules about smoking in workplaces, workers attitude about smoking and etc. Overally, it seems that the prevalence of cigarette smoking among Iranian male workers is lower than the other countries. In comparison to the national surveys among Iranian male adults, it seems that this prevalence is lower than general male adults. It should be noted that there is a prohibition of smoking in some workplaces. Also the lower prevalence of cigarette smoking among workers in comparison with general male adults could be related to recruiting process. Because of preventing some disorders and future outcomes, employers prefer to recruit healthier workers (30).

Co-occurrence and co-changing of risk-taking behaviors is one of the most important and effective approaches in the prevention programs. A lot of studies emphasized on the co-occurrence of risk-taking behaviors (31-33). Consistent with previous finding in the literature $(34,35)$, the present study showed that cigarette smoking strongly associated with other risk-taking behaviors (i.e., hookah smoking, alcohol use, and sexual risk behavior).

A great deal of research showed the association between ADHD and cigarette smoking. Persons with ADHD exhibit a higher prevalence of smoking, initiate smoking at an earlier age, and are more likely to be a regular smoker in comparison with their peers (36-38). Most of these studies were taken among children, adolescents and young adults. Recently a study among Czech adults showed a surprising result. The finding of this study indicated that the prevalence of cigarette smoking was lower among those with higher ADHD score (39). In the present study, although having ADHD was significantly associated with cigarette smoking in univariate analysis, but the results of

Table 3. Logistic regression analysis of the association between "cigarette smoking" and risk-taking behaviors and ADHD in a sample of Iranian workers

\begin{tabular}{|c|c|c|c|c|c|c|}
\hline \multirow[b]{3}{*}{ Variables } & \multicolumn{6}{|c|}{ Cigarette smoking(last year) } \\
\hline & \multicolumn{3}{|c|}{ Crude estimation } & \multicolumn{3}{|c|}{ Adjusted estimation } \\
\hline & OR & $95 \% \mathrm{CI}$ & $\mathrm{p}$ & OR & $95 \% \mathrm{CI}$ & $\mathrm{p}$ \\
\hline Age (year) & 1.06 & $1.04-1.07$ & $<0.001$ & 1.08 & $1.07-1.09$ & $<0.001$ \\
\hline Education (academic/nonacademic) & 0.55 & $0.45-0.66$ & 0.450 & --- & --- & --- \\
\hline Sensation seeking (yes/no) & 2.79 & $1.99-3.90$ & 0.001 & 1.57 & $1.04-2.36$ & 0.037 \\
\hline Experience of self- injury(yes/no) & 5.39 & $2.88-10.08$ & 0.001 & 1.59 & $0.54-4.69$ & 0.318 \\
\hline Hookah smoking (last year) & 5.30 & $3.79-7.39$ & $<0.001$ & 4.21 & $3.12-5.69$ & $<0.001$ \\
\hline Alcohol use (last year) & 6.05 & $4.74-7.72$ & $<0.001$ & 2.51 & $1.54-4.08$ & 0.005 \\
\hline Illicit drug use (lifetime) & 7.44 & $4.28-12.92$ & $<0.001$ & 2.33 & $0.98-5.51$ & 0.053 \\
\hline Sexual risk behavior (last year) & 4.21 & $1.95-9.09$ & 0.005 & 2.25 & $1.07-4.71$ & 0.037 \\
\hline ADHD (yes/no) & 1.98 & $1.09-3.60$ & 0.032 & 0.61 & $0.26-1.44$ & 0.200 \\
\hline Religiosity & 0.86 & $0.82-0.91$ & 0.001 & 0.95 & $0.91-0.99$ & 0.039 \\
\hline Anxiety (yes/no) & 1.77 & $0.96-3.28$ & 0.062 & 1.13 & $0.70-1.82$ & 0.550 \\
\hline Self-esteem (low/normal) & 2.47 & $1.42-4.29$ & 0.008 & 2.02 & $1.11-3.65$ & 0.028 \\
\hline
\end{tabular}


the final logistic regression model showed that this variable has no significant association with cigarette smoking. It seems that this association among adults and especially workers need further surveys.

The findings of this study are consistent with several previous research that demonstrated the role of religiosity in the prevention of cigarette smoking (40-42). Religious beliefs can be considered as a marker of risk and could be used along with other related factors to detection and implementation of interventional plans to prevent smoking. It should be noted that although religiosity has been reported to be inversely associated with cigarette smoking, Gillum indicated that people with firmer religious beliefs are more likely to under-report smoking leading to spurious claims (43).

Several aspects of this study can limit the usefulness of the results: first, the cross-sectional nature of the study serves only as a document for the association between independent factors and cigarette smoking status and does not indicate causality. Second, the generalization of the findings is limited to the workers of Kaveh Industrial City. Finally, some other confounders such as other psychiatric disorders were not assessed in this study.

\section{Conclusion}

In this study, we estimated the prevalence of cigarette smoking among workers. Results revealed that $13.1 \%$ of workers were regular smokers (daily or almost daily). The findings highlighted the protective effect of a higher score of religiosity. On the other hand, our study represents the co-occurrence of risk-taking behaviors. Consequently, focusing on specific programs in the workplace including interventions to enhance self-esteem, can be effective in lowering cigarette smoking prevalence. Also, the cooccurrence of risk-taking behaviors needs comprehensive interventions to reduce or prevent different behaviors simultaneously.

\section{Acknowledgment}

We would like to thank Mr. Karim Shahidi and Mr. Hadi Azani and Dr. Hamid Reza Baradaran for their great assistance in data collection and coordination with factories.

\section{Conflict of Interests}

The authors declare that they have no competing interests.

\section{References}

1. Word Health Organization. Prevalence of tobacco smoking 2019. Available from: https://www.who.int/gho/tobacco/use/en/

2. Forouzanfar MH, Afshin A, Alexander LT, Anderson HR, Bhutta ZA, Biryukov S, et al. Global, regional, and national comparative risk assessment of 79 behavioural, environmental and occupational, and metabolic risks or clusters of risks, 1990-2015: a systematic analysis for the Global Burden of Disease Study 2015. Lancet. 2016;388(10053):1659-724.

3. Reitsma MB, Fullman N, Ng M, Salama JS, Abajobir A, Abate $\mathrm{KH}$, et al. Smoking prevalence and attributable disease burden in 195 countries and territories, 1990-2015: a systematic analysis from the Global Burden of Disease Study 2015. Lancet. 2017;389(10082):1885-906.

4. Nemati S, Rafei A, Freedman ND, Fotouhi A, Asgary F, Zendehdel K. Cigarette and water-pipe use in Iran: Geographical distribution and time trends among the adult population; A pooled analysis of national STEPS surveys, 2006-2009. Arch Iran Med. 2017;20(5):295.

5. Chin DL, Hong O, Gillen M, Bates MN, Okechukwu CA. Cigarette smoking in building trades workers: the impact of work environment. Am J Ind Med. 2012;55(5):429-39.

6. Syamlal G, King BA, Mazurek JM. Tobacco product use among workers in the construction industry, United States, 2014-2016. Am J Ind Med. 2018;61(11):939-51.

7. Ham DC, Przybeck T, Strickland JR, Luke DA, Bierut LJ, Evanoff BA. Occupation and workplace policies predict smoking behaviors: analysis of national data from the current population survey. J Occup Environ. 2011;53(11):1337.

8. Farrelly MC, Evans WN, Sfekas AE. The impact of workplace smoking bans: results from a national survey. Tobacco Control. 1999;8(3):272-7.

9. Kim BG, Pang DD, Park YJ, Lee JI, Kim HR, Myong JP, et al. Heavy smoking rate trends and related factors in Korean occupational groups: analysis of KNHANES 2007-2012 data. BMJ Open. 2015;5(11):e008229.

10. Aubin HJ, Rollema H, Svensson TH, Winterer G. Smoking, quitting, and psychiatric disease: a review. Neurosci Biobehav Rev. 2012;36(1):271-84

11. Lasser K, Boyd JW, Woolhandler S, Himmelstein DU, McCormick D, Bor DH. Smoking and mental illness: a populationbased prevalence study. JAMA. 2000;284(20):2606-10.

12. Kessler RC, Adler L, Barkley R, Biederman J, Conners CK, Demler $\mathrm{O}$, et al. The prevalence and correlates of adult ADHD in the United States: results from the National Comorbidity Survey Replication. Am J Psychiatry. 2006;163(4):716-23.

13. Visser SN, Danielson ML, Bitsko RH, Holbrook JR, Kogan MD, Ghandour RM, et al. Trends in the parent-report of health care provider-diagnosed and medicated attention-deficit/hyperactivity disorder: United States, 2003-2011. J Am Acad Child Adolesc Psychiatry. 2014;53(1):34-46. e2.

14. Rhodes JD, Pelham WE, Gnagy EM, Shiffman S, Derefinko KJ, Molina BS. Cigarette smoking and ADHD: An examination of prognostically relevant smoking behaviors among adolescents and young adults. Psychol Addict Behv. 2016;30(5):588.

15. Mosalanejad M, Mosalanejad L, Lashkarpour K. Prevalence of ADHD among students of Zahedan University of Medical Science in Iran. Iran J Psychiatry Behav Sci. 2013;7(2):83.

16. Hamzeloo M, Mashhadi A, Salehi Fadardi J. The Prevalence of ADHD and Comorbid Disorders in Iranian Adult Male Prison Inmates. J Atten Disord. 2016;20(7):590-8.

17. Amin-Esmaeili M, Rahimi-Movaghar A, Yunesian M, SahimiIzadian E, Moinolghorabaei M. Trend of smoking among students of Tehran University of Medical Sciences: results from four consecutive surveys from 2006 to 2009. Med J Islam Repub Iran. 2013;27(4):168-78.

18. Abbasi-Ghahramanloo A, Fotouhi A, Zeraati H, Rahimi-Movaghar A. Prescription drugs, alcohol, and illicit substance use and their correlations among medical sciences students in Iran. Int J High Risk Behav Addict. 2015;4(1):e21945.

19. Sadeghi-Bazargani H, Amiri S, Hamraz S, Malek A, Abdi S, Shahrokhi H. Validity and reliability of the Persian version of Conner's adult ADHD rating scales: observer and self-report screening versions. J Clin Res Gov. 2014;3(1):42-7.

20. Anbarlouei M, Sarbakhsh P, Dadashzadeh H, Ghiasi A, Ataieasl $\mathrm{M}$, Dorosti A, et al. Cigarette and hookah smoking and their relationship with self-esteem and communication skills among high school students. Health Promot Perspect. 2018;8(3):230-6.

21. Hossein Kaviani H, Mousavi A S. Psychometric properties of the Persian version of Beck Anxiety Inventory (BAI). Tehran Univ Med J. 2008;66(2):136-40.

22. Jewell NP. Statistics for epidemiology: Chapman and Hall/CRC; 2003.

23. Jamal A, Phillips E, Gentzke AS, Homa DM, Babb SD, King BA, et al. Current Cigarette Smoking Among Adults - United States, 2016. Morb Mortal Wkly Rep. 2018;67(2):53-9.

24. Greenhalgh E, Bayly M, Winstanley MH. 1.3 Prevalence of smoking - adults. In Scollo, MM and Winstanley, MH [editors]. Tobacco in Australia: Facts and issues. Melbourne: Cancer Council Victoria; 2019. Available from http://www.tobaccoinaustralia. org.au/chapter-1-prevalence/1-3-prevalence-of-smoking-adults. 
25. Meysamie A, Ghalehtaki R, Ghodsi S, Esteghamati A, Mohammad $\mathrm{K}$, Etemad $\mathrm{K}$, et al. Trend of cigarette smoking in Iranian adult population from 2000 to 2011 based on four national surveys. Soc Determ Health. 2017;3(3):148-59.

26. Graber JM, Worthington K, Almberg KS, Meng Q, Rose CS, Cohen RA. High Cigarette and Poly-Tobacco Use Among Workers in a Dusty Industry: New Jersey Quarry Workers. J Occup Environ Med. 2016;58(4):e133-9.

27. Rachiotis G, Behrakis PK, Vasiliou M, Yfantopoulos J. Quality of life and smoking among industrial workers in Greece. Med Lav. 2006;97(1):44-50.

28. Barros MV, Nahas MV. [Health risk behaviors, health status selfassessment and stress perception among industrial workers]. Rev Saúde Pública . 2001;35(6):554-63.

29. Divinakumar KJ, Patra P, Prakash J, Daniel A. Prevalence and patterns of tobacco use and nicotine dependence among males industrial workers. Ind Psychiatry J. 2017;26(1):19-23.

30. Chowdhury R, Shah D, Payal AR. Healthy Worker Effect Phenomenon: Revisited with Emphasis on Statistical Methods - A Review. Indian J Occup Environ Med. 2017;21(1):2-8.

31. Abbasi-Ghahramanloo A, Heshmat R, Safiri S, Esmaeil Motlagh M, Ardalan G, Mahdavi-Gorabi A, et al. Risk-Taking Behaviors in Iranian Children and Adolescents: A Latent Class Analysis Approach: Caspian IV Study. J Res Health Sci. 2018;18(4).

32. Afrashteh S, Ghaem H, Abbasi-Ghahramanloo A. Clustering and combining pattern of high-risk behaviors among Iranian university students: A latent class analysis. J Res Health Sci. 2017;17(4).

33. Brooks FM, Magnusson J, Spencer N, Morgan A. Adolescent multiple risk behaviour: an asset approach to the role of family, school and community. J Public Health. 2012;34(suppl_1):i48-i56.

34. Allahverdipour H, Abbasi-Ghahramanloo A, Mohammadpoorasl A, Nowzari P. Cigarette smoking and its relationship with perceived familial support and religiosity of university students in Tabriz. Iran J Psychiatry. 2015;10(3):136.

35. Abbasi-Ghahramanloo A, Rahimi-Movaghar A, Zeraati H, Fotouhi A. Pattern of substance use among students of medical sciences in Tehran, Iran: A latent class analysis. J Subst Use. 2018;23(6):64854.

36. Tercyak KP, Audrain-McGovern J. Personality differences associated with smoking experimentation among adolescents with and without comorbid symptoms of ADHD. Subst Use Misuse. 2003;38(14):1953-70

37. Rodriguez D, Tercyak KP, Audrain-McGovern J. Effects of inattention and hyperactivity/impulsivity symptoms on development of nicotine dependence from mid adolescence to young adulthood. J Pediatr Psychol. 2007;33(6):563-75.

38. Murphy KG, Flory K. Motives underlying smoking in college students with ADHD. Am J Drug Alcohol Abuse. 2017;43(3):350-9.

39. Weissenberger S, Ptacek R, Vnukova M, Raboch J, KlicperovaBaker M, Domkarova L, et al. ADHD and lifestyle habits in Czech adults, a national sample. Neuropsych Dis Treat. 2018;14:293.

40. Rabinowitz YG, Mausbach BT, Atkinson PJ, Gallagher-Thompson D. The relationship between religiosity and health behaviors in female caregivers of older adults with dementia. Aging Ment Health. 2009;13(6):788-98.

41. Farhadinasab A, Allahverdipour H, Bashirian S, Mahjoub H. Lifetime Pattern of Substance Abuse, Parental Support, Religiosity, and Locus of Control in Adolescent and Young Male Users. Iran J Public Health. 2008;37(4):88-95.

42. Afrashteh S, Ghaem H, Gholami A, Tabatabaee HR, AbbasiGhahramanloo A. Cigarette smoking patterns in relation to religiosity and familial support among Iranian university students: A Latent Class Analysis. Tob Induc Dis. 2018;16(33):1-7.

43. Gillum R. Religiosity and the validity of self-reported smoking: the Third National Health and Nutrition Examination Survey. Rev Relig Res. 2005:190-6. 